Article

\title{
The Environmental Sustainability of Nations: Benchmarking the Carbon, Water and Land Footprints against Allocated Planetary Boundaries
}

\section{Kai Fang ${ }^{1,2, *}$, Reinout Heijungs ${ }^{1,3}$, Zheng Duan ${ }^{4}$ and Geert R. de Snoo ${ }^{1}$}

1 Institute of Environmental Sciences (CML), Leiden University, P.O. Box 9518, Leiden 2300RA, The Netherlands; E-Mails: r.heijungs@vu.nl (R.H.); snoo@cml.leidenuniv.nl (G.R.S.)

2 School of Public Affairs, Zhejiang University, Yuhangtang Road 688, Hangzhou 310058, China

3 Department of Econometrics and Operations Research, VU University Amsterdam, De Boelelaan 1105, Amsterdam 1081HV, The Netherlands

4 Faculty of Civil Engineering and Geosciences, Delft University of Technology, Stevinweg 1, Delft 2628CN, The Netherlands; E-Mail: duanzheng2008@gmail.com

* Author to whom correspondence should be addressed; E-Mail: fang@cml.leidenuniv.nl; Tel.: +31-71-527-1486; Fax: +31-71-527-7434.

Academic Editors: Arjen Y. Hoekstra, Ashok K. Chapagain and Guoping Zhang

Received: 18 May 2015 / Accepted: 12 August 2015 / Published: 19 August 2015

\begin{abstract}
Growing scientific evidence for the indispensable role of environmental sustainability in sustainable development calls for appropriate frameworks and indicators for environmental sustainability assessment (ESA). In this paper, we operationalize and update the footprint-boundary ESA framework, with a particular focus on its methodological and application extensions to the national level. By using the latest datasets available, the planetary boundaries for carbon emissions, water use and land use are allocated to 28 selected countries in comparison to the corresponding environmental footprints. The environmental sustainability ratio (ESR) - an internationally comparable indicator representing the sustainability gap between contemporary anthropogenic interference and critical capacity thresholds - allows one to map the reserve or transgression of the nation-specific environmental boundaries. While the geographical distribution of the three ESRs varies across nations, in general, the worldwide unsustainability of carbon emissions is largely driven by economic development, while resource endowments play a more central role in explaining national performance on water and land use. The main value added of this paper is to provide concrete evidence of the usefulness of the proposed framework in
\end{abstract}


allocating overall responsibility for environmental sustainability to sub-global scales and in informing policy makers about the need to prevent the planet's environment from tipping into an undesirable state.

Keywords: environmental sustainability assessment; environmental footprints; planetary boundaries; sustainability gap; environmental sustainability ratio; nations

\section{Introduction}

\subsection{Environmental Sustainability Assessment (ESA): A Brief Overview}

Humanity has entered a new era of sustainability challenges, the Anthropocene, in which the planet's environment is under significant pressure from social, economic, and demographic forces. In striving to prevent our society and future generations from tipping into disastrous states, sustainable development has remained one of the primary policy goals in the large majority of countries over the world [1]. The United Nations is scheduled to announce the Sustainable Development Goals by 2015, an evolving program that is under way to replace the Millennium Development Goals [2]. In measuring progress towards sustainable transitions and human well-being, it is necessary to create ways to assess environmental sustainability - a non-negotiable prerequisite for the economic and social pillars of sustainable development [3].

There have been many attempts to promote transparency and standardization of environmental sustainability assessment (ESA). One example is the ecological footprint, which compares human demand for bioproduct provision and carbon sinks with the relevant regenerative and assimilative capacity of the biosphere, thereby explaining why the current economy lives on the depletion of exhaustible stocks rather than on sustainable flows [4]. Apparently, this is by no means the only way of implementing ESA. The Environmental Sustainability Index [5] and its updated version, the Environmental Performance Index [6], for instance, have attracted considerable interest and discussions among science, policy, and in the media. Other influential ESA tools include the Environmental Quality Index [7], the Index of Environmental Friendliness [8], the Environmental Vulnerability Index [9], and the Critical Natural Capital [10].

Despite the continuous efforts made by a large group of researchers, there is no agreement on the most appropriate definition and method for ESA. Nevertheless, on the basis of an in-depth discussion performed in our previous study [11], we come up with some key observations regarding ESA: (1) the essential property of ESA is the comparison of current environmental conditions and critical capacity thresholds; (2) a descriptive pressure indicator responsible for what is currently happening to the environment has no relation to ESA unless it is benchmarked against a critical threshold indicator serving as a reference; (3) the difficulty in prediction of environmental boundaries poses a major challenge to ESA due to uncertainties surrounding the position of the thresholds; and (4) the estimates of ESA are normally expressed either in difference or in ratio, but not in both. 


\subsection{Environmental Footprints: Descriptive Pressure Indicators}

To represent how much pressure humanity exerts on the Earth's ecosystems, an expanding list of environmental footprints has been introduced to the scientific community over recent years $[12,13]$. Irrespective of the prevalence of footprint-style indicators, there remains a considerable amount of confusion and controversy regarding the concepts and methodologies [14-16]. A consequence is that there is, to our knowledge, not yet an explicit and agreed definition of footprints. To bring transparency to this issue, here we propose a general definition as follows: environmental footprints are tools that communicate human-driven pressure on the environment and, in some cases, the associated impacts. To our understanding, this is probably the common ground on which most, if not all, footprint studies depend crucially.

The ecological footprint [17], the water footprint [18], and the carbon footprint [19] have been subject to a wide range of scientific scrutiny. A striking overlap has been identified between the ecological and carbon footprints in terms of fossil carbon emissions. To avoid double counting, it is suggested to exclude the energy component from the ecological footprint accounting and to refer to the remainder as "land footprint" which accounts for the pressure associated with actual land use [20,21]. Collectively, the carbon, water and land footprints are able to capture the complicated effects of human activities, including carbon emissions (climate change), water use and land use, on the Earth's system processes.

\subsection{Planetary Boundaries: Critical Threshold Indicators}

The planetary boundaries framework offers a set of quantitative capacity thresholds for vital Earth system processes based on recent scientific evidence [22]. Even though planetary boundaries were not designed to downscale to smaller scales [23], there is an increasing demand for allocation to national and regional levels at which numerous environmental policies are formulated and executed with broad participation of stakeholders. This has triggered a growing interest in the development of approaches to detecting sustainability limits and to anticipating critical transitions at multiple scales [24-26]. Furthermore, based on recent understanding of the complexity of the Earth system functioning and resilience, Steffen et al. [23] have implemented updates of planetary boundaries, with a special focus on those that are spatially heterogeneous and show threshold behaviors at sub-global scales.

As one of the most widespread systems of threshold indicators, planetary boundaries present, for the first time, an up-to-date comprehensive estimate of critical values for nine Earth system processes at the global scale. A threshold-behavioral distinction has been made between "systemic processes" with explicit global thresholds, such as climate change, and "aggregated processes" without strong evidence of planetary-scale thresholds, such as water use and land use [22]. For systemic processes, in theory their planetary boundaries can be readily allocated to nations and regions through a top-down approach. The reality is, however, that the control variables used for all three systemic planetary boundaries (climate change, ocean acidification and stratospheric ozone depletion) are concentrations or intensity indices ( $\mathrm{such}$ as $2{ }^{\circ} \mathrm{C}$ ) that do not allow for yielding remaining budgets and for dividing into country-specific shares. To overcome this issue, all such threshold values must be translated into quantities of flow characters, such as $\mathrm{Gt} /$ year of carbon dioxide $\left(\mathrm{CO}_{2}\right)$. 
Things get more complicated when it comes to aggregated processes, for which no top-down approach is applicable, because a truly global threshold behavior hardly exists unless boundaries at a local or regional level have been repeatedly transgressed for large parts of the world [22,27]. More specifically, the environmental boundaries for water and land use are essentially dependent on the local availability and scarcity of freshwater and land and thus vary over space, while the planetary carbon boundary potentially can be applied to any specific region, regardless of location. All this points to a key methodological limitation of the present planetary boundaries framework: It is inherently incapable of downscaling environmental boundaries from the planetary level to smaller levels because of the inappropriate control variables and the omission of sub-global dynamics that are critical to both regional and global sustainability.

\subsection{The Need for Integrating Footprints and Boundaries into ESA}

In summary, environmental footprints and planetary boundaries fall into the categories of descriptive pressure indicators and critical threshold indicators, respectively. Biophysical elements underlying the two have the potential to constitute an evolving representation of ESA, where a distinction between "sustainable" and "unsustainable" activities is made by showing to what extent a planetary or regional environmental boundary has been approached or exceeded by the corresponding footprint [20]. This is accompanied by the recognition that planetary boundaries for both systemic and aggregated processes are necessary to allocate to a national or regional level in support of decision making [11].

In this paper, we first introduce an integrated framework that makes complementary use of environmental footprints and planetary boundaries originating from two isolated research fields. We then apply this framework to a comparative analysis of national-scale environmental sustainability by measuring and integrating three pairs of footprints and boundaries, and finally offer a picture of the overall environmental performance of different countries. The purpose of our analysis is to provide novel insights into the development of a robust methodology for ESA (Section 2), and to present available knowledge on the environmental sustainability of 28 nations in a coherent way with respect to carbon emissions, water use and land use (Section 3). Section 4 comprises discussions on the contribution of selected variables to national performance, the consistency with other estimates, and the policy relevance of a weighted index to trade-offs issues. Conclusions and some final remarks are drawn in Section 5.

\section{Methods}

\subsection{A Footprint-Boundary ESA (F-B ESA) Framework}

Having recognized the benefits of integrating footprints and boundaries for ESA, Fang et al. [11] establish a footprint-boundary ESA (F-B ESA) framework for the joint use of a set of footprint and boundary metrics in a systematic way. It comprises the definitions of ecological footprints and planetary boundaries, the development of the concepts of sustainability gap, policy gap and implementation gap, and a technical discussion of the measurement of regional and local environmental footprints and boundaries and of the trade-offs between different sustainability gaps. 
The logic is to identify some crucial environmental issues, select suitable footprint indicators for each of them, demonstrate at which level the environmental boundaries are most likely to exist, determine the appropriate methods for quantifying relevant boundary indicators, and finally account for the resulting sustainability gaps. To ensure the consistency and reliability of the F-B ESA framework, it is argued that the footprint and boundary metrics should be measured in such a way that they match well with each other.

The F-B ESA framework challenges, for the first time, the isolation of the two research communities and opens the door to collaborative research in defining and assessing environmental sustainability at multiple scales. Its primary purpose is to inform policy makers on the sustainability gap between current environmental conditions and critical capacity thresholds, indicating whether or not human activities have fallen into an unsustainable state that may result in undesirable environmental changes, with detrimental or even disastrous consequences for the population of a region or the world. By use of the F-B ESA framework, environmental sustainability and unsustainability can be explicitly defined and distinguished from a footprint-boundary perspective:

- Environmental sustainability: A safe state in which the footprint of human activities placed on the environment is kept within boundary of capacity.

- Environmental unsustainability: An unsafe state in which the footprint of human activities placed on the environment exceeds boundary of capacity.

\subsection{Selecting Key Environmental Footprints for Cross-National Analysis}

In view of the ever-expanding list of environmental footprints, we have to restrict our analysis to some key footprints that have proved useful in measuring human pressure on the environment. We have therefore made a selection of footprints with a focus on their scientific robustness, documentation, and applicability. Our selection contains the carbon footprint, the water footprint (consisting of the green and blue water footprints) and the land footprint for the following reasons: (1) the three footprints are sufficiently mature to support policy makers and the public in accounting for the appropriation of natural capital in terms of carbon emissions, water use and land use [20], in particular for cross-national analysis that will be undertaken in the remainder of this paper; (2) in the inventory stage, no obvious overlap has been observed among the three footprints, which allows one to avoid counting the same resources or emissions in duplicate [20]; (3) of the aggregated processes, water use and land use are identified as the only two which are likely to show threshold behaviors suited for measurement on a nation-specific basis [24]; and (4) the reason not to include grey water is that its data presently available are related to nitrogen loads, which mostly contribute to groundwater pollution and therefore ought to be compared with the waste assimilative capacity of groundwater [28], for which the data at the national level are not easily obtainable.

\subsection{Data Sources}

We conduct an analysis on the latest datasets available. All data relate to nation-specific carbon, water and land footprints. In the absence of better datasets for the same year, we tentatively assemble these data with the assumption that they are sufficiently comparable. Given data availability, 
28 countries have been chosen in this study for empirical analysis, namely, Australia, Austria, Belgium, Brazil, Canada, China, Denmark, Finland, France, Germany, India, Indonesia, Ireland, Italy, Japan, Mexico, Netherlands, Norway, Poland, Russia, South Africa, South Korea, Spain, Sweden, Switzerland, Turkey, UK, and USA. Data sources are juxtaposed in Table 1. Note that, for convenience, we name either the world-average values or the global values as global values.

Table 1. Data sources for the estimation of the footprint and boundary metrics.

\begin{tabular}{cccc}
\hline Footprint Metric & Data Source & Boundary Metric & Data Source \\
\hline Carbon footprint & EUREAPA 2011 [29] & Carbon boundary & IPCC 2014 [30]; PRB 2009 [31]; UNEP 2014 [32] \\
Water footprint & Mekonnen et al. 2011 [33] & Water boundary & FAO 2012 [34] \\
Land footprint & GFN 2012 [35] & Land boundary & GFN 2012 [35] \\
\hline
\end{tabular}

\subsection{Allocating Selected Planetary Boundaries to Nations}

In accordance with the footprints chosen, three planetary boundaries (carbon, water and land) are supposed to be reconceived in a way that allows for allocating to the national level and for consistency and commensurability with the footprint metric. Clearly the top-down process applies to the downscaling of planetary carbon boundary. For the planetary boundaries for water and land, a different approach is taken due to the geographical heterogeneity of these natural resources. Thus, in the following, we address the two categories of environmental boundaries separately.

\subsubsection{Downscaling Planetary Carbon Boundary on a Per Capita Basis}

It is perceived as a consensus that human-induced carbon emissions contribute to global warming and climate change no matter where emissions take place [30]. The global nature of planetary carbon boundary allows us to allocate quotas of emission permits using a top-down approach. Technically, partitioning the "cake" can be fulfilled in a number of ways, based on the criterion of population size, economic output, territorial area, or historical responsibility. Each of these has relative merits and demerits, and because of this, we consider it as a normative or political issue more than a scientific issue [11]. Nevertheless, in this paper, national population is selected as the basis for allocating planetary carbon boundary to country-specific shares, for reasons of simplicity and comparability with the national water boundary and land boundary which will be evaluated on a per capita basis as well but with different methods.

It should be noted that considerations of fairness and equity are not fully accounted for in this case, as the carbon boundary is built on a scientific and political consensus reached by the global community that from now on every human being ought to be equally responsible for the reduction in carbon emissions in order to limit global warming to $2{ }^{\circ} \mathrm{C}$ above the preindustrial level [30,36]. That is also the premise of the planetary carbon boundary set by Rockström et al. [22]. This corresponds to a maximum of 18-25 Gt $\mathrm{CO}_{2}$-eq./year for annual carbon emissions by 2050, where non-carbon greenhouse gas (GHG) emissions have been translated into carbon emissions by using global warming potentials [12,32]. With the global population of 6.8 billion in 2009 [31], we adopt the mean value of $3.1 \mathrm{t} \mathrm{CO}_{2}$-eq./year for both planetary and national carbon boundaries per capita. 


\subsubsection{Quantifying National Water and Land Boundaries on a Resource Availability Basis}

The distribution of worldwide water and land resources is geographically heterogeneous, with implications for local or regional environment in most cases. This calls for the need to take spatial variations in resource scarcity into account [37,38]. In theory, nation-specific environmental boundaries for resource use can be quantified either through the aggregation of local or regional scarcity thresholds, if present, or through the overall estimate of resource availability within the national borders. The first approach, which likely leads to more accurate results, is constrained by the lack of data on local resource depletion with evidence of threshold behavior and of knowledge on the cumulative effects of multiple regions (i.e., it is unclear whether the national environmental boundary simply amounts to the sum, maximum or minimum of regional environmental boundaries). By contrast, the second approach under current conditions has been found preferable to measure national water and land boundaries [24].

It has been demonstrated that $90 \%$ of the green water availability throughout the world is required to maintain the operation of critical ecosystem services irrespective of human actions [39,40], and that a reference value for the green water availability is not yet available [12]. All this allows the blue water availability to be an approximation to the national water boundary, defined as annually renewable water supply minus environmental flow requirements for ecological health within the border of a country [41]. Consideration of these environmental flows is necessary to avoid disastrous impacts associated with water scarcity [42]. Following Rockström et al. [22] who proceeded with planetary water boundary on the explicit understanding that undesirable or even disastrous consequences may trigger if the ratio of water withdrawal to the renewable supply surpasses $40 \%$, this paper defines the water boundary for a country as $40 \%$ of the total renewable water resources - the sum of the internal and external water resources of that country. Data for the renewable water resources of individual countries are obtained from the Food and Agriculture Organization's (FAO) database AQUASTAT [34]. In theory, the sum of the water boundaries (not per capita) for all nations should be equal to the total PB (not per capita). However, there are some reasons that explain why the two numbers would not be identical, such as the variation in data sources, and the double counting of the external water resources in both the upstream country and downstream country.

In the original version of the planetary boundaries framework, land boundary was assessed by the criterion that a maximum of $15 \%$ of Earth surface is allowed to convert to cropland [22]. This brings the risk of underestimating the role of crop production in human survival. In practice, converting land for farming would, on the contrary, promote a great deal of welfare and therefore deserving of positive evaluation [43]. In the updated version the control variable for land boundary has altered to be the percentage of the forest land area, with a minimum threshold of $75 \%$ [23]. But this remains the limitation of incompleteness. To overcome this concern, we adopt biocapacity, an aggregate indicator that measures the critical thresholds for biologically productive land use [4], as a proxy of national land boundaries that are needed to reach self-sufficiency. In contrast to Rockström et al.'s contention, the biocapacity assumes that the most suitable land available will be planted to cropland, and that the second, third, fourth and last choices are forest land, grassland, fishing ground, and built-up land, respectively [44]. Data for the revised national land boundary per capita are derived from [35]. 


\subsection{Measuring the Sustainability Gap: Two Alternative Indicators}

As yet, neither the footprint metric nor the boundary metric is able to capture both sides of the sustainability issues; therefore, they should rather be used complementarily to allow for quantitative estimates of the extent to which human pressure on the environment has approached or exceeded the critical capacity thresholds. This leads to the concept of sustainability gap, which aims at providing policy makers with a practical measure of anthropogenic interference with the planet's environment. In principle, a sustainability gap can be measured in two alternative ways, either by subtracting the footprint metric from the respective boundary metric, or by dividing the footprint metric by the respective boundary metric. We elaborate on these in the following subsections. Before that, we define the following symbols:

- $F_{i, j}$ is the converted footprint for environmental issue $i$ for country $j$.

- $B_{i, j}$ is the converted boundary for environmental issue $i$ for country $j$.

where the index $i$ runs over carbon, water and land, and the index $j$ runs over the 28 nations. Because all indicators are measured on an annual basis, the symbols $\mathrm{F}$ and $\mathrm{B}$ are expressed in the units of $\mathrm{kg}$ $\mathrm{CO}_{2}$-eq./year for carbon, $\mathrm{m}^{3} /$ year for water, and ha/year for land.

\subsubsection{Environmental Sustainability Distance (ESD)}

The environmental sustainability distance (ESD) refers to the difference between a footprint and the relevant boundary:

$$
E S D_{i}=F_{i}-B_{i}
$$

In cases where $E S D_{i}>0$, the footprint metric exceeds the corresponding boundary metric and leads to environmental unsustainability, and vice versa.

\subsubsection{Environmental Sustainability Ratio (ESR)}

The environmental sustainability ratio (ESR) refers to the ratio of a footprint to the relevant boundary:

$$
E S R_{i}=F_{i} / B_{i}
$$

In cases where $E S R_{i}>1$, the footprint metric exceeds the corresponding boundary metric and leads to environmental unsustainability, and vice versa.

\subsubsection{The Comparative Advantage of ESRs over ESDs in a Cross-National Context}

In principle, both ESDs and ESRs that depict how far countries are from their individual environmental boundaries are adequate for representing the magnitude of the (un)sustainability of a single or multiple environmental issue. As a result, there is no need to make use of them at the same time. The difference between ESDs and ESRs is the way of representing sustainability gaps in absolute terms of the former and in relative terms of the latter. An ESR that serves as a dimensionless indicator suffices to provide comparable values for human pressure not only across regions but also across environmental issues, rather than having to convert disparate values into a single unit, as is the case for 
an ESD. This comparative advantage enables a better performance of ESRs, especially in a cross-national context. We, therefore, choose to utilize ESRs for the following analysis.

\subsubsection{Production-Based versus Consumption-Based ESR}

In defining an ESR, the terms in the quotient are made up by the footprint and the boundary. For environmental footprints, a distinction has already been made between production-based and consumption-based footprints [45,46]. Following this logic, we can contrast production-based ESRs and consumption-based ESRs. Both viewpoints are legitimate and have a policy value. A production-based ESR refers to the degree of environmental unsustainability due to activities within the border of a country. A consumption-based ESR ignores the activities for exported products, but, on the other hand, includes the activities that take place abroad and that are associated with products imported by the region of concern. ESA and the ESRs, therefore, depend on the definition and the perspective.

\section{Results}

To be consistent across our analysis, the same coloring system is employed to graph the ESRs for all the three environmental issues, namely carbon emissions (climate change), water use, and land use. Further, we choose to display the $\log (\mathrm{ESR})$ instead of an ESR, to ensure that a ratio of $2 / 1$ and a ratio of $1 / 2$ are treated equivalently, for instance. We consider this to be superior to data-dependent normalization depending exclusively on what are included in the sample. Countries with environmental sustainability $(\mathrm{ESR}<1$ or $\log (\mathrm{ESR})<0$ ) are shown in green colors, and countries with environmental unsustainability $(\mathrm{ESR}>1$ or $\log (\mathrm{ESR})>0$ ) are shown in red colors. $\mathrm{ESR}=1$ or $\log (\mathrm{ESR})=0$ is the magical value. However, one cannot claim to be so precise. For this reason, we define the $\log (\mathrm{ESR})$ between -0.25 and 0.25 to be the risky intervals, which corresponds to an ESR between 0.56 and 1.78. While an ESR bounded by less than 0.56 might not be the sufficient conditions for environmental sustainability, we believe that it is a prerequisite for that. In the following, we examine the ESRs for the 28 nations in terms of carbon emissions, water use and land use, respectively.

\subsection{The Environmental Sustainability of National Carbon Emissions}

In the case of carbon emissions, the global ESR is estimated at 2.42, indicating that the human economy emits nearly 2.5 times the permissible GHGs, beyond which global warming by 2050 is very likely to cross the $2{ }^{\circ} \mathrm{C}$ target. This estimate highlights the worldwide unsustainability of the Earth's climate system arising from immoderate carbon emissions. Figure 1 presents a "heat map" of national-scale environmental sustainability associated with carbon emissions. India is the only country operating within the carbon boundary, with an ESR of 0.54 . The three countries falling in the risky intervals between sustainability and unsustainability are Indonesia, Brazil and China, with an ESR of $0.72,1.24$ and 1.31, respectively. The rest of the countries go beyond the stable environmental state, of which the ESRs vary considerably, ranging from 1.79 for Turkey to 8.62 for USA. Twenty-two nations have ESRs higher than the global value, and this is perhaps partly due to the fact that many of the 
countries investigated here are developed countries which tend to rely more heavily on carbon-intensive goods and services.

As a genuine "natural availability" is lacking and is replaced by a per capita share of the planetary carbon boundary, there are several large countries that already exceed this share by far, such as USA and China. While the USA has been replaced by China as the largest carbon emitter in the world [47], our analysis demonstrates that its ESR exceeds 5.5 times that of China and thus remains the primary contributor to the unsustainability of the global climate system. This discrepancy partially results from the difference between production-based accounting and consumption-based accounting - two competing approaches that have been in conflict to some extent. Moreover, the advances in carbon boundary accounting in this study offers a way to bridge the science-policy interface, as it encompasses scientific and political consensus on tipping points for sustainability under global climate change.

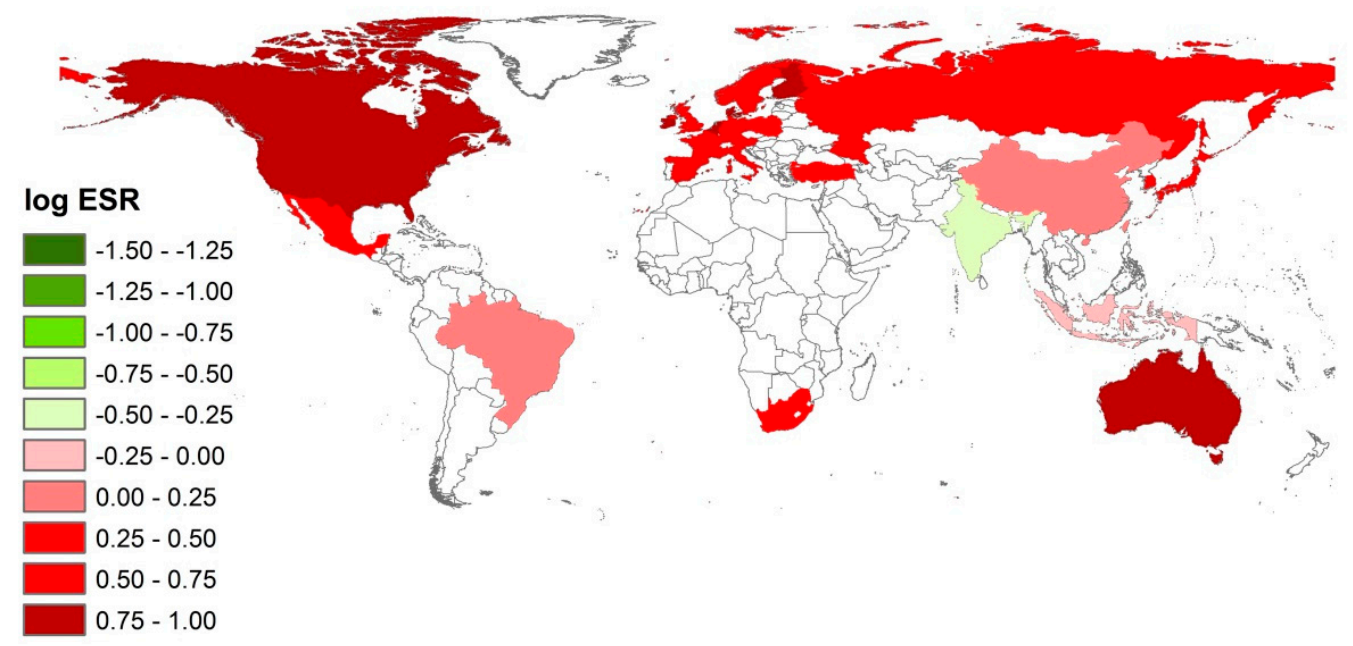

Figure 1. The environmental sustainability ratios of nation-specific carbon emissions for 28 nations.

\subsection{The Environmental Sustainability of National Water Use}

Unlike carbon emissions, we benchmark the national water footprint against the national water availability within the political boundary, rather than comparing national performance on a global base which is only applicable to systemic processes. As such, the method used is specifically constructed to yield a conservative estimate of the ESRs of some countries. Consequently, another 11 countries are found to fall into the risky intervals, with ESRs ranging from 0.57 for USA to 1.66 for Poland. We attribute the "unsustainable" label to five nations, among which Denmark has the highest ESR of 3.07, followed by South Africa (2.87), South Korea (2.46), Spain (2.23), and Belgium (2.05). The water ESR is 0.48 on average in the world. Lower-than-average ESRs are found in 11 countries, ranging from 0.04 for Norway to 0.43 for Switzerland, as shown in Figure 2. They are, in fact, those having ESRs less than the lower limit of the risky intervals as well and therefore can be classified as sustainable nations. The remaining one which is also sustainable is The Netherlands, whose internal water resources account for only $12 \%$ and the external account for the remainder of $88 \%$. 
While the distribution of the national water ESRs is in general agreement with monthly water scarcity in the world's river basins monitored by Hoekstra et al. [41], one should be aware that non-transgression of national water boundary does not necessarily mean environmental sustainability locally and regionally. For instance, though Australia has an ESR of 0.24 merely, large parts of eastern Australia suffer from severe water scarcity due to the disproportionate withdrawal of water resources compared to availability [41]. However, we are convinced that the ESA of water use at the national scale still makes sense, because, so far, most studies are limited to the basin-level at which little information could be provided on nation-wide water management policy. However, a technical challenge remains in the approximation of the " $40 \%$ rule", as it fails to capture the spatial variations in the thresholds for water withdrawal within individual nations; this is, nevertheless, a general shortcoming in present methods for defining national water boundaries [48].

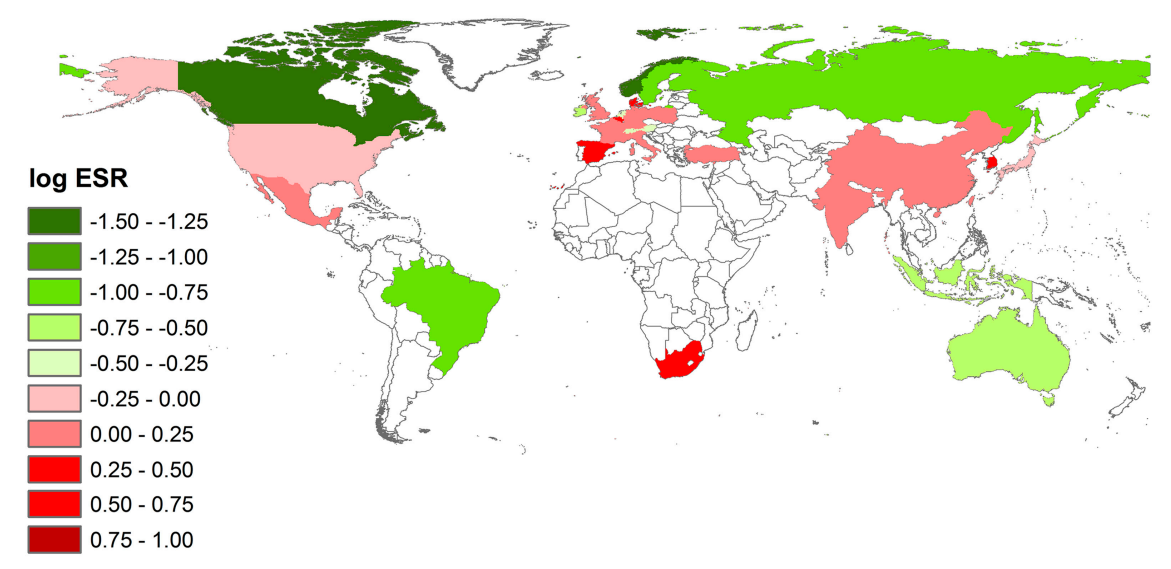

Figure 2. The environmental sustainability ratios of nation-specific water use for 28 nations.

\subsection{The Environmental Sustainability of National Land Use}

Figure 3 describes which countries approach the individual national land boundaries, and which already overstep. At the global scale, the land ESR is estimated to be 0.67, suggesting that human demand for food, fiber and timber products has been operating in a risky situation in which the regenerative capacity of land supply becomes a limiting factor for sustainable land use. In keeping with this assessment, similar risky situations can be witnessed in 17 countries, accounting for $61 \%$ of the countries investigated. Seven countries are able to maintain the maximum capacity within their national land boundaries. Of the seven, Finland and Canada have the lowest ESRs, with a value of 0.15 and 0.18 , respectively. The rest of the 28 countries constitute the top-four list, whose land requirements for self-sufficiency under current bioproductivity are much higher than the available resources, with notable ESRs ranging from 2.29 for South Korea to 2.77 for The Netherlands. 


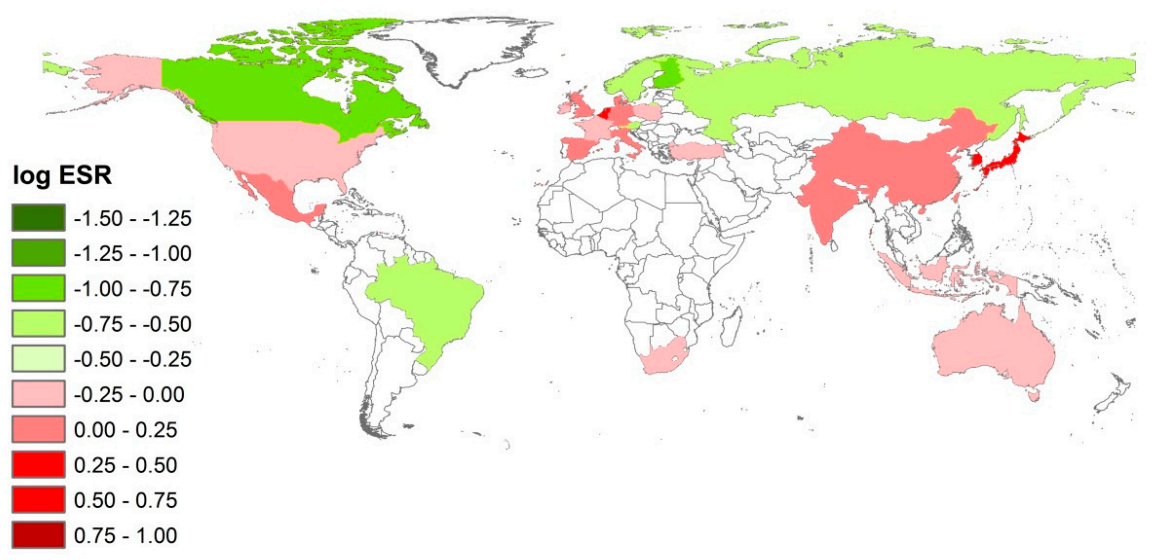

Figure 3. The environmental sustainability ratios of nation-specific land use for 28 nations.

As a whole, the geographical distribution of national ESRs for land use follows a pattern somewhat similar to that for water use. Likewise, the driving forces behind unsustainable land use are complex, including not only the mismatch between region-specific population and land supply, which leads to environmental consequences local-to-regional in scale and which in aggregate may be of national significance, but also the displacement of land use to other countries through international trade $[49,50]$. In this sense, the land footprint and boundary measured in this paper are informative for policy makers who seek to evaluate national performance on land use in a comparative sense. This valuable information is likely to get lost if replaced by the simplistic metrics representing the percentage of land use converted to cropland, as is done by Rockström et al. [22], or the percentage of forest land area, as is done by Steffen et al. [23].

\section{Discussion}

The analysis carried out provides a preliminary integrated assessment of environmental sustainability for 28 countries. Our findings highlight the national-level heterogeneity of both anthropogenic interference and capacity thresholds for carbon emissions, water use and land use. Although the determinants of the sustainability gaps associated with the three environmental issues are definitely complex and may vary across countries, we argue that the complementary distribution of nations between emissions and resource use (water and land use) presented in this study can offer important information to policy makers. To that end, a correlation analysis is undertaken by a regression of log-transformed data to measure the strength of potential linear relationship between the ESR and three variables: (a) Gross Domestic Product (GDP) per capita; (b) renewable water resources (RWRs) per capita; and (c) population density (PD), as will be illustrated below.

As seen in Figure 4a, very few countries have already achieved a decoupling of economy from carbon emissions, as evident from the highly significant positive correlation between GDP per capita and the carbon ESR $\left(R^{2}=0.8622\right)$. By contrast, the ESRs of water and land use have no correlation with GDP per capita since their correlation coefficients do not pass the significance test of the regression with 95-percentile confidence intervals $(p<0.05)$. An opposite situation is observed when it comes to Figure $4 b$, in which per capita RWRs have a non-significant correlation coefficient with the carbon ESR, while being closely correlated to that of land use $\left(R^{2}=0.5958\right)$ and, not surprisingly, 
significantly to that of water use $\left(R^{2}=0.8756\right)$. Figure $4 \mathrm{c}$ exposits positive significant correlations between the PD and the ESRs of water use $\left(R^{2}=0.6310\right)$ and land use $\left(R^{2}=0.6157\right)$, while the latter is not as strong as commonly thought. One reason for that might be the salient differences across land types and nations in bioproductivity - the key parameter for determining the land footprint and land boundary.

The correlation coefficient between each pair of the explanatory variables indicates that, for the 28 countries on average, approximately $86 \%$ of the variation in the $\log (\mathrm{ESR})$ of carbon emissions can be explained by $\log (\mathrm{GDP} /$ capita). This is quite different from the cases of water use and land use, where between $53 \%$ and $96 \%$ of the variation can be explained by $\log (\mathrm{RWR} / \mathrm{capita})$ or $\log (\mathrm{PD})$. We further test the three variables together in a multiple regression (Table 2), and see that all the three ESRs are explained very well by the three variables. GDP is a major driving factor for the carbon ESR, but not for that of water and land. For water, the RWRs are highly significant, and for land, the interplay turns out to be more complicated and there is no clear driving factor.

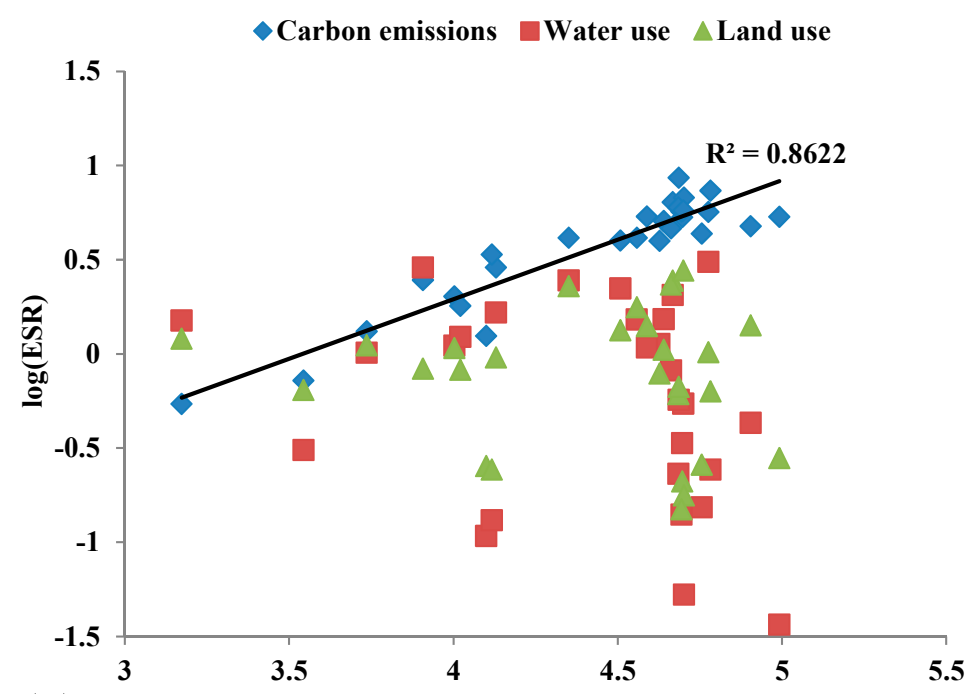

(a)

$\log$ (GDP/capita)

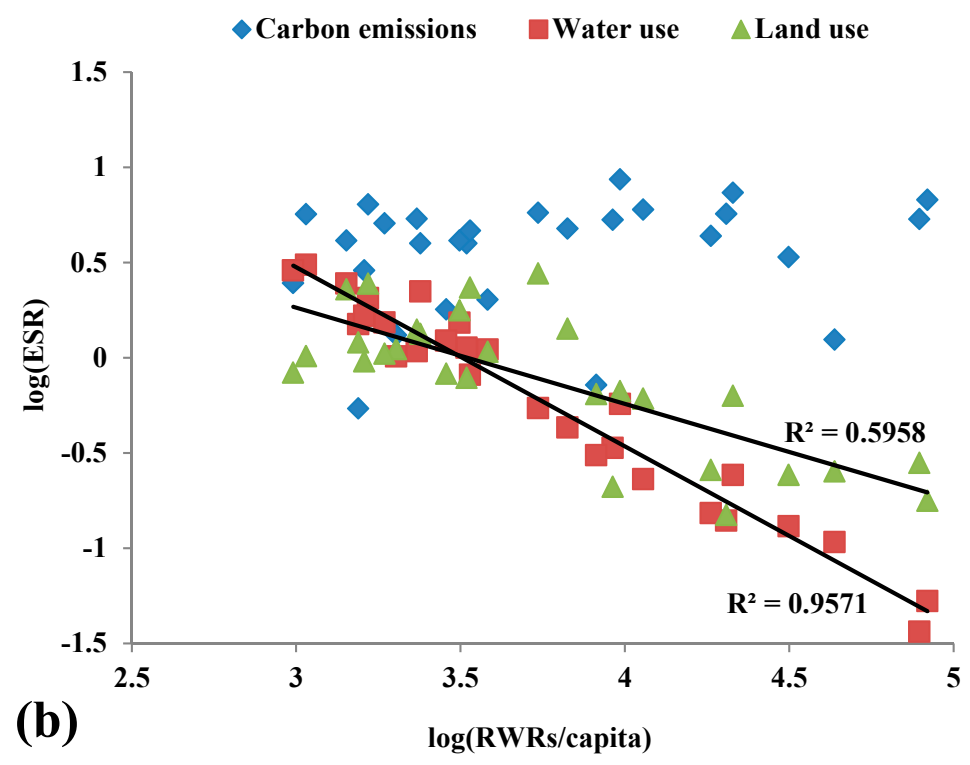

Figure 4. Cont. 


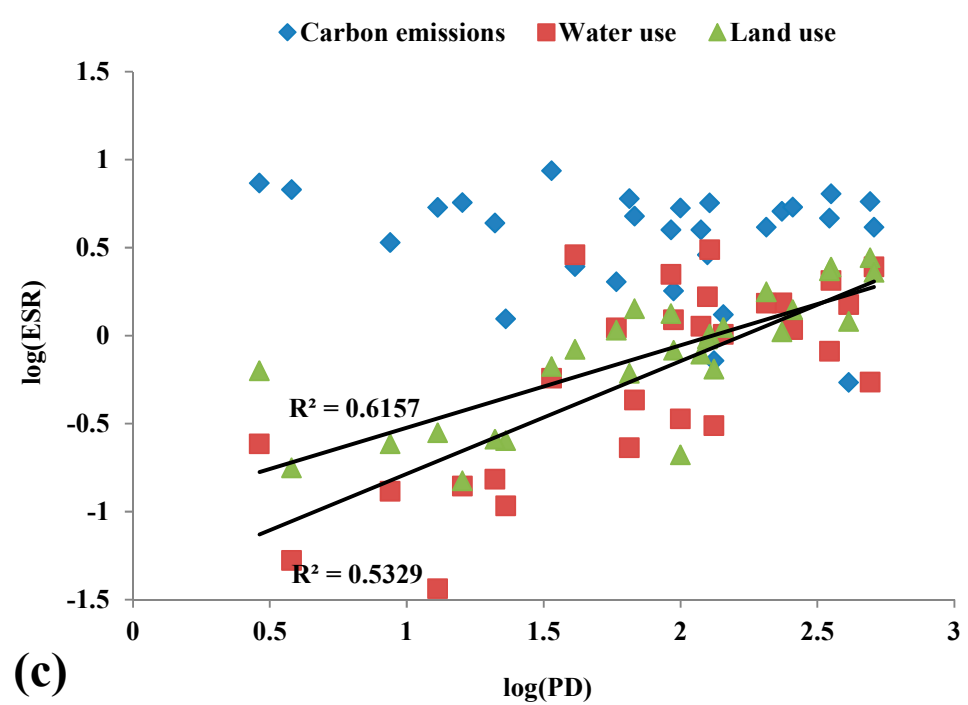

Figure 4. Correlations between $\log (\mathrm{ESR})$ and (a) $\log (\mathrm{GDP} /$ capita); (b) $\log (\mathrm{RWRs} / \mathrm{capita})$; (c) $\log (\mathrm{PD}) . R^{2}$ is the coefficient of determination (the square of the correlation coefficient). Lines with a non-significant correlation $(p>0.05)$ are not shown.

Table 2. Multiple regression of $\log (\mathrm{ESRs})$ on three $\log$-transformed variables. $b$ is the regression coefficient, $S E$ its standard error, and $p$ the $p$-value of the $t$-test for $\beta=0 . R^{2}$ is the coefficient of determination of the regression model, $F$ its $F$-statistic, and $p$ the significance of the overall model.

\begin{tabular}{cccccccccccccc}
\hline \multirow{2}{*}{$\log ($ ESR $)$} & \multicolumn{3}{c}{$\log ($ GDP $)$} & \multicolumn{4}{c}{$\log ($ RWRs $)$} & \multicolumn{3}{c}{$\log ($ PD) } & \multicolumn{4}{c}{ Model Fit } \\
\cline { 2 - 13 } & $\boldsymbol{b}$ & $\boldsymbol{S} \boldsymbol{E}$ & $\boldsymbol{p}$ & $\boldsymbol{b}$ & $\boldsymbol{S} \boldsymbol{p}$ & $\boldsymbol{p}$ & $\boldsymbol{b}$ & $\boldsymbol{S} \boldsymbol{E}$ & $\boldsymbol{p}$ & $\boldsymbol{R}^{2}$ & $\boldsymbol{F}$ & $\boldsymbol{p}$ \\
\hline Carbon & 0.658 & 0.049 & 0.000 & -0.149 & 0.061 & 0.023 & -0.110 & 0.055 & 0.055 & 0.889 & 64.226 & 0.000 \\
Water & 0.054 & 0.050 & 0.290 & -1.037 & 0.063 & 0.000 & -0.097 & 0.056 & 0.097 & 0.963 & 209.248 & 0.000 \\
Land & 0.128 & 0.098 & 0.204 & -0.299 & 0.123 & 0.023 & 0.275 & 0.109 & 0.019 & 0.698 & 18.524 & 0.000 \\
\hline
\end{tabular}

In summary, the unsustainability of carbon emissions is largely driven by the stage of economic development on which a nation finds itself, while resource endowments play a more important role in the degree of unsustainable water and land use (PD can be seen as the inverse of per capita land resources). These findings confirm the fundamental distinction between the systemic and aggregated processes. In addition, Figure 5 shows that the global ESR values for the three environmental issues agree well with other estimates of the ratios of pressures to thresholds in the literature, supporting the conclusions of earlier studies on the transgression of planetary carbon boundary and on the reserve of planetary water and land boundaries. Nevertheless, a major divergence is encountered in the case of carbon emissions, where the planetary carbon boundary is measured based either on joint use of two control variables - atmospheric $\mathrm{CO}_{2}$ concentration and radiative forcing - not allowing to downscale, as is done by Rockström et al. [22], or on an integrated alternative- $\mathrm{CO}_{2}$-equivalent emissions - a mass-based indicator that is more inclusive and expressed in the same unit of the carbon footprint, as is done by Hoekstra et al. [12] and by our study. 


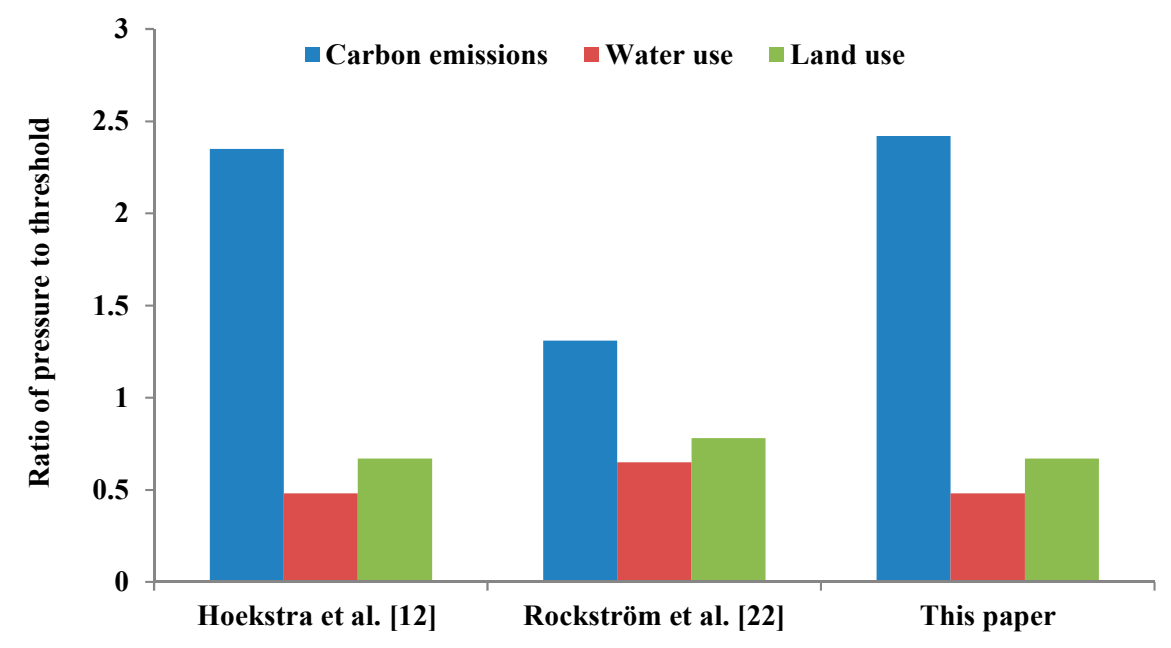

Figure 5. Comparison of the ratios of pressures to thresholds at the global level between our estimate and the estimates in the literature.

As such, it is our conviction that the F-B ESA framework allows one to improve the performance of the planetary boundaries accounting on integrity, transparency and, more importantly, the harmonization with footprint indicators. Another prominent merit of the F-B ESA framework is its capacity to outline the methodology for assessing trade-off issues, such as one country and another that generates a lower carbon footprint but a higher water footprint. One solution is not only to benchmark each national environmental footprint against the respective environmental boundary in commensurable units but also to aggregate different sustainability gaps between them into a composite index through weighting factors. The rationale behind this is that weighting the footprint and boundary metrics simultaneously enables a more meaningful evaluation of trade-offs than weighting either footprints or boundaries on their own, in particular when policy makers are in great need of a quantitative comparison of the overall performance of nations on environmental sustainability [11].

To illustrate the idea of weighting without pretending to give a conclusive answer, for each single country, we purposely bring together the three ESRs into an ESR index (ESRI) with an assigned weighting factor of $1 / 3$. All resulting ESRI scores for the 28 countries are presented in ascending order (Figure 6). Specifying an ESRI of 1 as the threshold value for national-scale overall environmental sustainability, we find that only Brazil and Indonesia maneuver within their individual safe operating space, and that the other 26 countries are in the state of environmental unsustainability, with ESRIs ranging from 1.08 for India to 3.63 for Belgium. By carrying out a multiple regression of $\log (\mathrm{ESRI})$ on $\log$ (GDP), $\log$ (RWRs) and $\log (\mathrm{PD})$ (Table 3 ), we find that the ESRI is explained quite well by GDP and the RWRs, but that the PD is not helpful in explaining the weighted ESRI according to 95-percentile confidence intervals. As a whole, the ranking of countries reflects the overall performance of national-scale environmental sustainability influenced by multi-factors, thereby justifying the use of the ESRI in providing a policy-oriented solution to trade-off issues. 


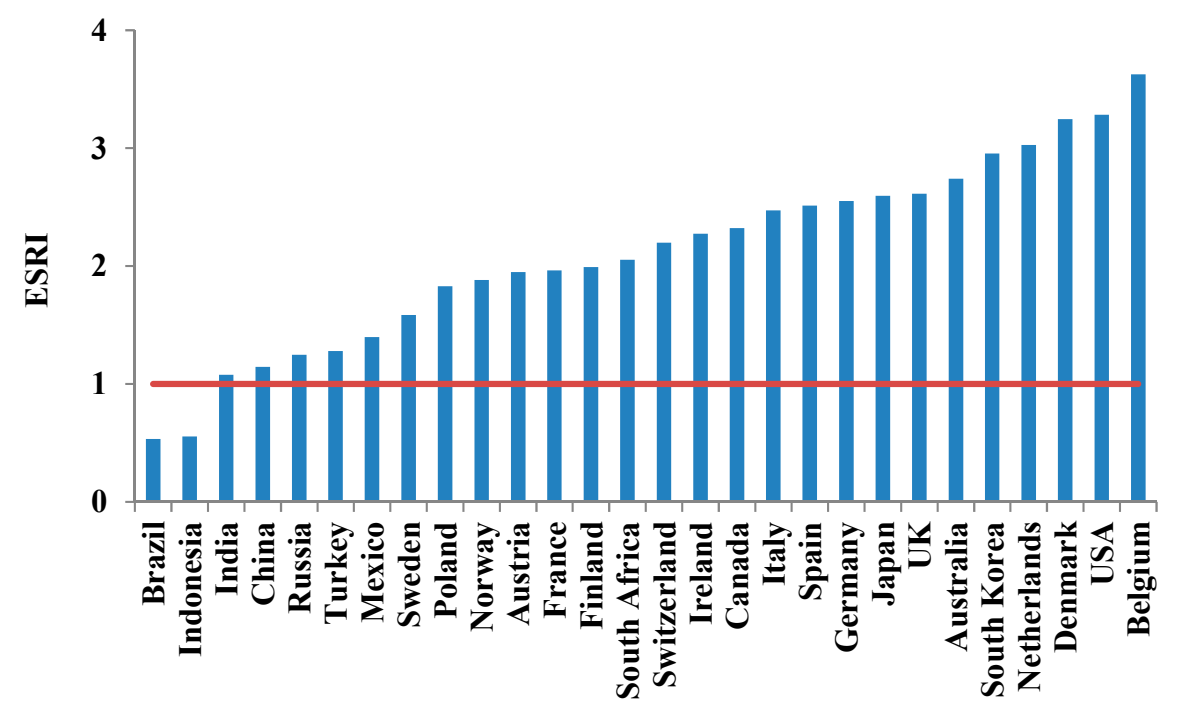

Figure 6. The index of environmental sustainability ratio for each of the 28 nations.

Table 3. Multiple regression of $\log (\mathrm{ESRI})$ on three $\log$-transformed variables. See Table 2 for an explanation of the symbols.

\begin{tabular}{ccccccccccccc}
\hline & \multicolumn{3}{c}{$\log ($ GDP $)$} & \multicolumn{3}{c}{$\log ($ RWRs $)$} & \multicolumn{3}{c}{$\log ($ PD) } & \multicolumn{3}{c}{ Model fit } \\
\cline { 2 - 13 } & $\boldsymbol{b}$ & $\boldsymbol{S} \boldsymbol{p}$ & $\boldsymbol{p}$ & $\boldsymbol{b}$ & $\boldsymbol{S} \boldsymbol{E}$ & $\boldsymbol{p}$ & $\boldsymbol{b}$ & $\boldsymbol{S} \boldsymbol{E}$ & $\boldsymbol{p}$ & $\boldsymbol{R}^{2}$ & $\boldsymbol{F}$ & $\boldsymbol{p}$ \\
\hline $\log (\mathrm{ESRI})$ & 0.412 & 0.049 & 0.000 & -0.255 & 0.061 & 0.000 & -0.066 & 0.055 & 0.240 & 0.766 & 26.117 & 0.000 \\
\hline
\end{tabular}

As is the case for all weighting practices, equal weighting that assumes equal importance of the carbon, water and land ESRs in our case has been steeped in controversy [51]. That is to say, it would be preferred if the final results are presented at both aggregate and disaggregate levels. Other weighting schemes may easily be implemented, if desired, to investigate the sensitivity of final results to weighting factors. For instance, Tuomisto et al. [52] define weighting factors for the aggregation of diverse local-specific environmental issues in a way similar to the calculation of the global ESRs calculated here, so that one can weigh the seriousness of different issues at the global level. As an aside, from a broader point of view, the ESRs that describe the gap between the footprint and boundary metrics can be understood as a measure of environmental impacts. In this sense, weighting and aggregating ESRs into a single-value ESRI would facilitate the ongoing development of integrated environmental impact assessment—a topic that remains a priority for future endeavors [53].

\section{Conclusions}

It has been increasingly acknowledged that environmental sustainability serves as a critical prerequisite for the economic and social pillars of sustainable development. Environmental sustainability analysis, therefore, deserves priority in sustainability science [54]. This paper develops ways to allocate planetary boundaries to the national scale and to benchmark against environmental footprints, with the intention of bridging the disciplinary gap and, more importantly, of making use of the synergies for ESA. By means of the F-B ESA framework, we are able to uncover the sustainability gaps of carbon emissions, water use and land use for 28 countries and the whole world. The well accordance with previous studies at the global scale allows our study to be as a whole reliable and 
reproducible. By examining the correlation between the resulting ESRs and selected explanatory variables, we also discuss certain possible driving factors for unsustainable resource use patterns. Furthermore, seeking to meet the rising policy demand for an overall picture of the environmental sustainability of nations, a weighted composite index for ESRs (i.e., ESRI) is launched for snapshotting and ranking nations' overall performance on the three environmental issues investigated.

The main value added of the paper is to provide concrete evidence of how the F-B ESA framework makes it possible to allocate global responsibility for environmental sustainability to individual countries where environmental policy initiatives massively take place. It is not difficult to expect application extensions to sub-national scales, such as regions, cities, and organizations, on which environmental issues are dealt with even more often. A key difficulty concerns the disparate scaling effects of the systemic processes and the aggregated processes. For carbon emissions, for instance, the unambiguous global nature enables the carbon boundary to be one of the few planetary boundaries that can be downscaled to the national level through top-down approaches that seem to be a normative or political issue more than a scientific issue. Conversely, water and land boundaries are in many cases a sub-national problem, for which reliable local assessments could only be fulfilled by the access to high-resolution data for local-scale resource availability. The real challenges are therefore a mix of downscaling and upscaling, as well as a convergence of scientific and political considerations.

Admittedly, we realize that the analysis presented is limited in the capacity to capture the full complexity of sustainability, as proved by the crude data gathering, the exclusion of many environmental issues by design, and the orientation towards macro- or meso-level that hampers the allocation of overall responsibility to a single process or product at the micro-level [55]. A further critical point is that, although benchmarking the green and blue water footprints against the blue water availability creates a solution to the overly optimistic estimate of planetary water boundary [56,57], this comparison is flawed in the sense that the scopes of the water footprint and boundary metrics are not identical. There is another type of inconsistency that should be resolved in the follow-up work, as exemplified between carbon emissions and water and land use. To improve the comparability of studies that define environmental sustainability from authors' point of view, further work needs to specify the precise realms of application of the production-based and consumption-based ESRs. But regardless of the choice, it is preferable to define the footprint and boundary metrics along the same principle, so that both numerator and denominator are either production-based or consumption-based. In addition, the investigation of the driving forces behind sustainability gaps is far from an exhaustive factorial analysis, even though it manages to provide an interesting basis for discussion on the importance and complexity of economic, natural and demographic factors for understanding national performance on environmental sustainability. Besides, the use of equal weighting is debatable with high uncertainty in the final estimate. This, however, is due to the recognition that trade-offs between sustainability gaps, in many cases, cannot be tackled without any form of weighting. Anyhow, in response to all these challenges that have to be confronted in implementing and developing the F-B ESA framework, we call for multidisciplinary and interdisciplinary collaboration between the fields of environmental footprints and planetary boundaries. 


\section{Acknowledgments}

Kai Fang is supported by China Scholarship Council-Leiden University Joint Program, financed by China Scholarship Council (20113005).

\section{Author Contributions}

Kai Fang, Reinout Heijungs and Geert R. de Snoo conceived and designed the research; Zheng Duan contributed to analytical tools; Kai Fang and Reinout Heijungs analyzed the data and wrote the paper. All authors have read and approved the final manuscript.

\section{Conflicts of Interest}

The authors declare no conflict of interest.

\section{References}

1. Griggs, D.; Stafford-Smith, M.; Gaffney, O.; Rockström, J.; Öhman, M.C.; Shyamsundar, P.; Steffen, W.; Glaser, G.; Kanie, N.; Noble, I. Sustainable development goal for people and planet. Nature 2013, 495, 305-307.

2. Costanza, R.; Kubiszewski, I.; Giovannini, E.; Lovins, H.; McGlade, J.; Pickett, K.E.; Ragnarsdóttir, K.V.; Roberts, D.; Vogli, R.D.; Wilkinson, R. Time to leave GDP behind. Nature 2014, 505, 283-285.

3. Goodland, R.; Daly, H. Environmental sustainability: Universal and non-negotiable. Ecol. Appl. 1996, 6, 1002-1017.

4. Wackernagel, M.; Rees, W.E. Perceptual and structural barriers to investing in natural capital: Economics from an ecological footprint perspective. Ecol. Econ. 1997, 20, 3-24.

5. Samuel-Johnson, K.; Esty, D.C. Pilot Environmental Sustainability Index Report. In Proceedings of the World Economic Forum: Annual Meeting, Davos, Switzerland, 28 January 2000.

6. Esty, D.C.; Levy, M.A.; Srebotnjak, T.; de Sherbinin, A.; Kim, C.H.; Anderson, B. Pilot Environmental Performance Index; Yale Center for Environmental Law \& Policy: New Haven, CT, USA, 2006.

7. Steinhart, C.E.; Schierow, L.-J.; Sonzogni, W.C. An environmental quality index for the great lakes. J. Am. Water Resour. Assoc. 1982, 18, 1025-1031.

8. Puolamaa, M.; Kaplas, M.; Reinikainen, T. Index of Environmental Friendliness: $A$ Methodological Study; Official Statistics of Finland: Helsinki, Finland, 1996.

9. Kaly, U.; Briguglio, L.; McLeod, H.; Schmall, S.; Pratt, C.; Pal, R. Environmental Vulnerability Index (EVI) to Summarise National Environmental Vulnerability Profiles. SOPAC Technical Report 275, 1999. Available online: http://ict.sopac.org/VirLib/TR0275.pdf (accessed on 1 December 2014).

10. Sutton, P.; Costanza, R. Global estimates of market and non-market values derived from nighttime satellite imagery, land cover, and ecosystem service valuation. Ecol. Econ. 2002, 41, 509-527. 
11. Fang, K.; Heijungs, R.; de Snoo, G.R. Understanding the complementary linkages between environmental footprints and planetary boundaries in a footprint-Boundary environmental sustainability assessment framework. Ecol. Econ. 2015, 114, 218-226.

12. Hoekstra, A.Y.; Wiedmann, T.O. Humanity's unsustainable environmental footprint. Science 2014, 344, 1114-1117.

13. Čuček, L.; Klemeš, J.J.; Kravanja, Z. A review of Footprint analysis tools for monitoring impacts on sustainability. J. Clean. Prod. 2012, 34, 9-20.

14. Giampietro, M.; Saltelli, A. Footprints to nowhere. Ecol. Indic. 2014, 46, 610-621.

15. Kitzes, J.; Galli, A.; Bagliani, M.; Barrett, J.; Dige, G.; Ede, S.; Erb, K.; Giljum, S.; Haberl, H.; Hails, C.; et al. A research agenda for improving national Ecological Footprint accounts. Ecol. Econ. 2009, 68, 1991-2007.

16. Van den Bergh, J.C.J.M.; Grazi, F. Ecological footprint policy? Land use as an environmental indicator. J. Ind. Ecol. 2014, 18, 10-19.

17. Rees, W.E. Ecological footprint and appropriated carrying capacity: What urban economics leaves out. Environ. Urban. 1992, 4, 121-130.

18. Hoekstra, A.Y.; Hung, P.Q. Virtual Water Trade: A Quantification of Virtual Water Flows between Nations in Relation to International Crop Trade; Value of Water Research Report Series No. 11; UNESCO-IHE Institute for Water Education: Delft, The Netherlands, 2002.

19. Wiedmann, T.; Minx, J. A definition of "carbon footprint". In Ecological Economics Research Trends; Pertsova, C.C., Ed.; Nova Science Publishers: New York, NY, USA, 2008; pp. 1-11.

20. Fang, K.; Heijungs, R.; de Snoo, G.R. Theoretical exploration for the combination of the ecological, energy, carbon, and water footprints: Overview of a footprint family. Ecol. Indic. 2014, $36,508-518$.

21. O'Brien, M.; Schütz, H.; Bringezu, S. The land footprint of the EU bioeconomy: Monitoring tools, gaps and needs. Land Use Policy 2015, 47, 235-246.

22. Rockström, J.; Steffen, W.; Noone, K.; Persson, Å.; Chapin, F.S., III; Lambin, E.F.; Lenton, T.M.; Scheffer, M.; Folke, C.; Schellnhuber, H.J.; et al. A safe operating space for humanity. Nature 2009, 461, 472-475.

23. Steffen, W.; Richardson, K.; Rockström, J.; Cornell, S.E.; Fetzer, I.; Bennett, E.M.; Biggs, R.; Carpenter, S.R.; de Vries, W.; de Wit, C.A.; et al. Planetary boundaries: Guiding human development on a changing planet. Science 2015, 347, doi:10.1126/science.1259855.

24. Cole, M.J.; Bailey, R.M.; New, M.G. Tracking sustainable development with a national barometer for South Africa using a downscaled "safe and just space" framework. Proc. Natl. Acad. Sci. USA 2014, 111, E4399-E4408.

25. Dearing, J.A.; Wang, R.; Zhang, K.; Dyke, J.G.; Haberl, H.; Sarwar Hossain, M.; Langdon, P.G.; Lenton, T.M.; Raworth, R.; Brown, S.; et al. Safe and just operating spaces for regional social-ecological systems. Glob. Environ. Change 2014, 28, 227-238.

26. Smith, N.J.; McDonald, G.W.; Patterson, M.G. Is there overshoot of planetary limits? New indicators of human appropriation of the global biogeochemical cycles relative to their regenerative capacity based on "ecotime" analysis. Ecol. Econ. 2014, 104, 80-92.

27. Lewis, S.L. We must set planetary boundaries wisely. Nature 2012, 485, doi: 10.1038/485417a. 
28. Schyns, J.F.; Hoekstra, A.Y. The added value of water footprint assessment for national water policy: A case study for Morocco. PLoS ONE 2014, 9, e99705.

29. EUREAPA. Scenario Modelling and Policy Assessment Tool, 2011. Available online: https://www.eureapa.net (accessed on 15 October 2012).

30. Intergovernmental Panel on Climate Change (IPCC). Climate Change 2014: Synthesis Report 2014. Available online: http://www.ipcc.ch/pdf/assessment-report/ar5/syr/SYR_AR5_LONG ERREPORT.pdf (accessed on 6 January 2015).

31. Population Reference Bureau (PRB). World Population Data Sheet 2009. Available online: http://www.prb.org/pdf09/09wpds_eng.pdf (accessed on 25 March 2014).

32. United Nations Environment Programme (UNEP). The Emissions Gap Report 2014: A UNEP Synthesis Report. Available online: http://www.unep.org/publications/ebooks/emissionsgapreport 2014/portals/50268/pdf/EGR2014_LOWRES.pdf (accessed on 6 January 2015).

33. Mekonnen, M.M.; Hoekstra, A.Y. National Water Footprint Accounts: The Green, Blue and Grey Water Footprint of Production and Consumption. Volume 2: Appendices 2011. Available online: http://www.waterfootprint.org/Reports/Report50-NationalWaterFootprints-Vol2.pdf (accessed on 5 October 2012).

34. Food and Agriculture Organization of the United Nations (FAO). AQUASTAT 2012. Available online: http://www.fao.org/nr/water/aquastat/data/query/index.html (accessed on 30 January 2015).

35. Global Footprint Network (GFN). National Footprint Accounts 2012 Edition. Available online: http://www.footprintnetwork.org/images/article_uploads/National_Footprint_Accounts_2012_Edi tion_Report.pdf (accessed on 17 June 2015).

36. Rogelj, J.; McCollum, D.; O’Neill, B.C.; Riahi, K. 2020 emissions levels required to limit warming to below $2{ }^{\circ} \mathrm{C}$. Nat. Clim. Change 2013, 3, 405-412.

37. Aubauer, H.P. Development of ecological footprint to an essential economic and political tool. Sustainability 2011, 3, 649-665.

38. Hoekstra, A.Y. Human appropriation of natural capital: A comparison of ecological footprint and water footprint analysis. Ecol. Econ. 2009, 68, 1963-1974.

39. Bogardi, J.J.; Fekete, B.M.; Vörösmarty, C.J. Planetary boundaries revisited: A view through the "water lens". Curr. Opin. Environ. Sustain. 2013, 5, 581-589.

40. Rockström, J.; Gordon, L.; Folke, C.; Falkenmark, M.; Engwall, M. Linkages among water vapor flows, food production, and terrestrial ecosystem services. Conserv. Ecol. 1999, 3, Article 5.

41. Hoekstra, A.Y.; Mekonnen, M.M.; Chapagain, A.K.; Mathews, R.E.; Richter, B.D. Global monthly water scarcity: Blue water footprints versus blue water availability. PLoS ONE 2012, 7, e32688.

42. Gerten, D.; Hoff, H.; Rockström, J.; Jägermeyr, J.; Kummu, M.; Pastor, A.V. Towards a revised planetary boundary for consumptive freshwater use: Role of environmental flow requirements. Curr. Opin. Environ. Sustain. 2013, 5, 551-558.

43. Bass, S. Keep off the grass. Nat. Rep. Clim. Change 2009, 3, 113-114.

44. Borucke, M.; Moore, D.; Cranston, G.; Gracey, K.; Iha, K.; Larson, J.; Lazarus, E.; Morales, J.C.; Wackernagel, M.; Galli, A. Accounting for demand and supply of the biosphere's regenerative capacity: The National Footprint Accounts' underlying methodology and framework. Ecol. Indic.

2013, 24, 518-533. 
45. Peters, G.P. From production-based to consumption-based national emission inventories. Ecol. Econ. 2008, 65, 13-23.

46. Wiedmann, T. A review of recent multi-region input-output models used for consumption-based emissions and resource accounting. Ecol. Econ. 2009, 69, 211-222.

47. Zhang, Y.J. The impact of financial development on carbon emissions: An empirical analysis in China. Energy Policy 2011, 39, 2197-2203.

48. Nykvist, B.; Persson, Å.; Moberg, F.; Persson, L.; Cornell, S.; Rockström, J. National Environmental Performance on Planetary Boundaries: A Study for the Swedish Environmental Protection Agency; Stockholm Resilience Center \& Stockholm Environment Institute: Stockholm, Sweden, 2013.

49. Meyfroidt, P.; Lambin, E.F.; Erb, K.H.; Hertel, T.W. Globalization of land use: Distant drivers of land change and geographic displacement of land use. Curr. Opin. Environ. Sustain. 2013, 5, 438-444.

50. Weinzettel, J.; Hertwich, E.G.; Peters, G.P.; Steen-Olsen, K.; Galli, A. Affluence drives the global displacement of land use. Glob. Environ. Change 2013, 23, 433-438.

51. Wiedmann, T.; Barrett, J. A Review of the ecological footprint indicator-Perceptions and methods. Sustainability 2010, 2, 1645-1693.

52. Tuomisto, H.L.; Hodge, I.D.; Riordan, P.; Macdonald, D.W. Exploring a safe operating approach to weighting in life cycle impact assessment-A case study of organic, conventional and integrated farming systems. J. Clean. Prod. 2012, 37, 147-153.

53. Chapman, P.M.; Maher, B. The need for truly integrated environmental assessments. Integr. Environ. Assess. Manag. 2014, 10, 151-151.

54. Kates, R.W. What kind of a science is sustainability science? Proc. Natl. Acad. Sci. USA 2011, 108, 19449-19450.

55. Hoekstra, A.Y. The sustainability of a single activity, production process or product. Ecol. Indic. 2015, 57, 82-84.

56. Molden, D. The devil is in the detail. Nat. Rep. Clim. Change 2009, 3, 116-117.

57. Jaramillo, F.; Destouni, G. Comment on "Planetary boundaries: Guiding human development on a changing planet". Science 2015, 348, doi:10.1126/science.aaa9629.

(C) 2015 by the authors; licensee MDPI, Basel, Switzerland. This article is an open access article distributed under the terms and conditions of the Creative Commons Attribution license (http://creativecommons.org/licenses/by/4.0/). 